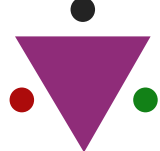 A Study on the Subjectivity of Nursing Students'
Perception of Obesity: Q-Methodology
}

IJCRR

Section: Healthcare

Sci. Journal Impact

Factor: 6.1 (2018)

ICV: 90.90 (2018)

\section{Sunyoung Jang}

Associate Professor, Department of Nursing, Hanseo University, South Korea

\section{ABSTRACT}

This research aims to examine subjectivity on obesity perceived by nursing students.

Method: The method to deal with data was $Q$ methodology. This research asked 21 students in the Nursing Department of $A$ College to sort 38 statements. Collected data were analyzed using QUANL PC Program.

Aim and Scope: The analysis found out 2 factors of subjectivity perception of obesity among those survey participants: obesity cause finding factor and obesity result perception factor.

Conclusion: The findings of this research will serve as basic data to understand perceptions of obesity among nursing students and to develop an educational program to teach them.

Key Words: Obesity, Nursing student, Subjectivity, Q-Methodology, Nurses.

\section{INTRODUCTION}

\section{BACKGROUND}

Obesity is the condition where, since ingested energy exceeds used energy, the remaining energy is accumulated as triglyceride in fat tissue in the body, and body weight exceeds normal weight by $20 \%$ or over, which can bring about various health problems. ${ }^{1}$ It has been reported that obesity is related to chronic diseases and that it is even related to life quality, self-esteem, depression, and stress.-5 Furthermore, those with extreme obesity have difficulty in finding jobs, and experience lack of self-confidence, isolation, and difficulty in social life and human relations. ${ }^{3,4}$

Plus, excessive consciousness of obesity triggers unreasonable diet, which then causes low body weight, another problem. Rapid change of social standards on beauty lead people to favour lookism and tall and slim body, and young people pay excessive attention to their body shapes. Even those with standard weights try to have slim bodies, putting more emphasis on body shape than on health. ${ }^{5,6}$ Obesity stress is stress one feels from one's obesity. Depending on how much acute one feels about one's body weight, obe- sity stress varies. Obesity stress can lead to weight regulating behaviour like irregular eating, overeating, and taking improper drugs. ${ }^{7-9}$ Obesity stress comes from two kinds of sources: internal stimulus from one's awareness of his or her obesity, and external stimuli such as opinions of his or her neighbours and mass media. Obesity is a disease in itself and can cause various kinds of chronic degenerative diseases. So, prevention and management of obesity are very important to maintain health. In contrast, distorted consciousness of one's body shape due to the favor of thin body shape becomes common among youngsters.

Nursing science is the scholastic field based on a sensitive understanding of oneself and other people, ${ }^{10}$ and, so, it is important for nursing students who are future nurses to be equipped with the ability to understand emotions of others and, to regulate the situations with their sensitivities. ${ }^{11}$ Nurses are core human power in public health and medical places, taking the biggest portion in such places and having the longest contacts with patients. And, they should provide patients with safe and high-quality nursing service to patients within given periods in rapidly changing public health and medical scenes. ${ }^{12}$ In nursing places, the subjectivity of perception of nurses has great effects on patients.

\section{Corresponding Author:}

Sunyoung Jang, Associate Professor, Department of Nursing, Hanseo University, South Korea. Email: sjang@hanseo.ac.kr

ISSN: 2231-2196 (Print) ISSN: $0975-5241$ (Online)

Received: 12.07 .2020

Revised: 14.08 .2020

Accepted: 16.09 .2020

Published: 06.10 .2020 
Thus, it is important to figure out the perceptions of nurses and nursing students.

However, there are not sufficient researches on obesity using nursing students as respondents. This research will deal with it using Q methodology. Q methodology allows us to understand the characteristics of different subjectivities. Such subjectivities are not determined by the researcher, but by the respondents themselves. ${ }^{13}$ As the perception of obesity is the unique experience of each person, Q methodology is proper to identify types of perception on it among nursing students.

Because humans are unique and human beings, individual and integrated research of subjectivity is inevitable to understand the perception of medical decisions. This research, using Q methodology, seeks to present basic data to enhance the ability to perform a role as a nurse in clinical sites by identifying the subjective perception types of nursing students in obesity.

Therefore, this research will examine the subjectivity structure of obesity among nursing students before they begin to work in nursing places. This research aims to provide basic data to develop nursing educational programs treating obese patients differently depending on the characteristics of subjectivity types.

\section{Aim and Objective}

The purposes of this research are to analyze subjectivity types of nursing students, and examine characteristics of different types, and to provide basic data in developing an educational program to teach nursing students before they begin to work in hospitals. Specific research purposes are as follows.

1) Categorize subjective perceptions of obesity among nursing students.

2) Analyze and describe the characteristics of different types of subjectivity on obesity among nursing students.

\section{MATERIALS AND METHODS}

\section{STUDY DESIGN}

To achieve research purposes, this research intended to examine the literature on obesity, and media sources, and discover types of subjectivity on obesity among nursing students.

\section{Q-POPULATION AND Q-SAMPLING SELECTION}

To extract statements on the effects of obesity, this research did a review of domestic and foreign literature on obesity, open-ended questionnaire, and individual in-depth interview. In the process, this research created the $\mathrm{Q}$ population consisting of over 200 statements. Besides, this research created another Q population composed of over 100 statements from domestic and foreign literature. From this Q population, it selected Q sample consisting of 38 statements.

\section{P-SAMPLE SELECTION METHOD}

Q method is a qualitative survey method focusing on subjectivity within the individual, and emphasizing the consistency of individual, rather than differences between people. It is based on small sample doctrine which assumes that if p-sample becomes large, many people can crowd around a specific component, and its characteristics are not revealed. ${ }^{14}$ P-sample in this study is 21 nursing school students who fully understood the purposes of the survey and voluntarily participated in the survey.

\section{Q-CLASSIFICATION AND DATA ANALYSIS METH- ODS}

Q sorting is the process where each of the participants belonging to p-sample makes the voluntary definition of induced abortion by sorting statements in Q-sample with forced normal distribution method..$^{14}$ The data were collected from 21 students in the Nursing Department of OO College with cards containing statements. The time spent by one participant in Q sorting was 30-45 minutes on average. The participant responded to each statement of the Q sample by pointing his or her preference on the 12 point scale ranging from strong negative to strong positive. Afterwards, on statements participants chose extremely positive or negative points, they were interviewed again. The data were under principle component factor analysis (varimax). Categorization into factors was done by considering the output from inputting factors with eigenvalue 1.0 or over and total explained variate. Collected data were coded with converted points from 1 to 12 in the forced distributed cards. By coding converted points in the order of Q sample number, and put under principle component factor analysis using the QUANL PC Program. ${ }^{15,16,17}$

\section{ETHICAL CONSIDERATION FOR RESEARCH SUB- JECTS}

Before the inception of the research, The participants were instructed that they have an option of discontinuation from the research of their interest and at any stage. Information was recorded for the rights and privacy of attendees which were programmed and stored.

The method of research and the recording of the interview contents were explained first before the meeting to ensure the autonomy of participants, the purpose of the research.

Then, the ethical aspects of the box were considered by obtaining verbal consent, receiving consent, and making compensation commensurate with participation in the research. As a measure not to violate the privacy of participants ac- 
cording to the principle of bad behaviour, It was informed that the interview would be used only for research purposes, and personal situations were kept secret while ensuring anonymity. Also, It was informed that the research results would be published and the participants could stop participating in the research anytime they want. To avoid revealing the identity of the research participant, the computer file was assigned a unique password for the researcher and all information that could identify the participant was deleted.

\section{RESULTS}

\section{STRUCTURE OF Q TYPE}

In order to divide the nursing students' perceptions of obesity by type, the answers to Q-samples were first collected and divided into two types. The distribution of 21 participants was 14 for the first type and 7 for the second type. As a result of dividing the group by similar responses to obesity, it was divided into two types.

Participants in this research conveniently were extracted from 21 nursing college students who were found to have experienced more than one clinical practice in the nursing department at $\mathrm{H}$ University. The general characteristics of the research subjects are as shown in [Table 1]. The total number of people surveyed total 21 with the average age being $22.19 \pm 1.83$, and $4.8 \%$ for boys and $95.2 \%$ for girls. Among them, $85.7 \%$ did not have a religion and $14.3 \%$ had a religion, and the number of weeks was $21.14 \pm 7.25$ weeks.

\section{Table 1: General Characteristics}

\begin{tabular}{cccccccc} 
Type & No Age Gender Grade Religion & $\begin{array}{c}\text { Number } \\
\text { of Prac- } \\
\text { tices (by } \\
\text { the week) }\end{array}$ \\
\hline Type 1 & 1 & 21 & F & 4 & No & 26 & .5979 \\
& 2 & 23 & F & 4 & No & 26 & .5839 \\
& 3 & 22 & F & 4 & No & 26 & .3533 \\
4 & 23 & F & 4 & Catholic & 24 & .6084 \\
5 & 21 & F & 4 & Christian & 26 & .8176 \\
7 & 22 & F & 4 & No & 26 & .3787 \\
10 & 21 & F & 4 & No & 24 & .7559 \\
11 & 22 & F & 4 & No & 24 & .8512 \\
12 & 21 & F & 4 & No & 24 & .3512 \\
13 & 22 & F & 4 & No & 24 & .1214 \\
16 & 21 & F & 4 & No & 26 & .2517 \\
19 & 22 & F & 3 & No & 6 & .6046 \\
20 & 25 & M & 3 & No & 6 & .3153 \\
21 & 22 & F & 4 & No & 20 & .4844
\end{tabular}

Table 1: (Continued)

\begin{tabular}{cccccccc} 
Type No Age Gender Grade Religion & $\begin{array}{c}\text { Number } \\
\text { of Prac- } \\
\text { tices (by } \\
\text { the week) }\end{array}$ \\
\hline Type 2 & 6 & 29 & F & 4 & Catholic & 26 & .7935 \\
& 8 & 21 & F & 4 & No & 24 & .3427 \\
& 9 & 21 & F & 4 & No & 24 & .8747 \\
14 & 21 & F & 3 & No & 8 & .2916 \\
15 & 22 & F & 4 & No & 20 & 1.2882 \\
17 & 22 & F & 4 & No & 26 & .2374 \\
18 & 22 & F & 3 & No & 8 & .5447 \\
\hline
\end{tabular}

*FWS: factor weight score

\section{SUBJECTIVITY AND TYPE-SPECIFIC CHARACTER- ISTICS OF OBESITY}

To analyze subjectivities on obesity among nursing students, this research described characteristics of each factor focusing on statements belonging to the factor. Q responses of $\mathrm{P}$ sample (participants) were divided into upper questions and lower questions, and 2 factors were extracted. In the Q method, someone who has high factor weight is considered as the typical or ideal person.

To analyze the characteristics of each factor, this research gave meanings to statements whose $\mathrm{z}$-scores are \pm 1.00 or over and explained them among all the classified statements. The number of participants whose factor weights are 1.0 or over and who belonged to factor 1 was 14 , and 7 in factor 2 .

The analysis of subjectivities on obesity of participants using QUANL pc program revealed 2 factors, which explained $46.25 \%$ of the total variance. factor 1 explained $38.26 \%$ of total variance; factor $2 \mathrm{did} 7.99 \%$. As the explanatory power of factor 1 is $38.26 \%$, the factor can be said to be able to explain subjectivity on obesity the best [Table 2]. Participants belonging to a specific factor responded similarly to the statement on obesity.

Table 2: Eigen Value, Variance, and Cumulative Percentage

\begin{tabular}{lcc} 
Hospitals & Type I & Type II \\
Eigen Value & 8.0341 & 1.6784 \\
Variance(\%) & .3826 & .0799 \\
Cumulative( \% ) & .3826 & .4625 \\
\hline
\end{tabular}

The correlation coefficients between the three factors are shown in [Table 3]. This shows the degree of similarity between the Type I and Type II. The correlation coefficient between type 1 and type 2 is 0.8101 . However, the correlation 
between factors in the $\mathrm{Q}$ method is different from the factor analysis method in the quantitative research, and since it focuses on finding the factors without presupposing the complete independence between the factors, there is no controversy over the method of factor extraction based on the high and low correlation.

\begin{tabular}{|c|c|c|}
\hline Hospitals & Type I & Type II \\
\hline Type I & 1.000 & .8010 \\
\hline Type II & - & 1.000 \\
\hline
\end{tabular}

\section{ANALYSIS OF SUBJECTIVITY PER FACTOR}

Subjectivity factors on obesity revealed by using the above method are as follows.

Obesity cause finding factor: 7 participants belonged to factor 1 . The statements to which those belonging to factor 1 expressed strong positive attitude were 'Obesity can cause diseases like high blood pressure, and diabetes, etc.' $(Z=2.14)$; 'Overeating by stress can cause obesity' $(Z=2.01)$; 'Obesity occurs by wrong eating habits and intake of too much nutrition' $(Z=127)$ [Table 4]. The participant whose factor weight was the highest $(0.8512)$ in factor 1 was participant No. 1 , and the statements to which the participant agreed the most were No. 10, No. 33, and No. 6.

The statements to which participants of factor 1 expressed the most negative responses were 'I think that my friends despise me because I am fat' $(Z=-1.70)$; 'Obesity makes me difficult to have a smooth relationship with colleagues, seniors and juniors' $(Z=-1.61)$. 'Obesity makes it difficult to form self-identity' $(Z=-1.48)$ [Table 4]. The participant in factor 1 whose factor weight was the lowest $(0.1214)$ was participant No. 13. The statements to which the participant agreed the most were No. 5, No. 1 and No. 7.

The characteristics of factor 1 are concern about the causes of obesity. Those people who belonged to factor 1 focused on causes of obesity such as stress, wrong eating habits, and frequency of eating out, and viewed that improvement of such things could reduce obesity. They viewed that obesity did not bring about social discrimination or other negative effects. Plus, they did not think that low self-esteem or self-management could generate obesity. Consequently, this research named factor 1 as 'obesity cause-finding factor'.

Obesity result perception factor: 7 participants belonged to factor 2. The statements to which those belonging to factor 2 expressed strong positive attitude were 'Obesity can cause diseases like high blood pressure, and diabetes, etc.' $(Z=2.46)$; 'Obesity occurs by wrong eating habits and intake of too much nutrition' $(Z=1.78)$; 'Obesity makes it impossible to wear clothes I want to' $(Z=1.52)$ [Table 4]. The participant whose factor weight was the highest (1.2882) in factor 2 was participant No. 15, and the statements to which the participant agreed the most were No. 10, No. 6, and No. 9.

The statements to which participants of factor 2 expressed the most negative responses were 'Obese person is considered as having a weak will and being low in scholastic scores' ( $\mathrm{Z}=$ 1.94); Obesity makes me difficult to have a smooth relationship with colleagues, seniors and juniors $(Z=-1.91)$ [Table 4]. The participant in factor 2 whose factor weight was the lowest $(0.2374)$ was participant No. 17 . The statements to which the participant agreed the most were No. 21, No. 1, and No. 27.

The characteristics of factor 2 are concern about the results of obesity. Those people belonged to factor 2 assumed that obesity was the results of bad eating habits and life attitudes, and would cause chronic diseases like high blood pressure and diabetes, etc. Plus, they assumed that obesity would cause the person to have inferiority complex on one's appearance, prevent him or her from wearing clothes as he or she wanted. They thought that the perception of obesity would differ depending on social cultures. However, they denied that obese people were weak in their wills, low in school grades, or would have difficulty in socializing with people around them. They also did not agree with the assumption that fat people tended to depend on other people around them or they could not receive love from their parents. They focused on the results of obesity, and they thought that if fat people recognized such results, and changed their habits, obesity rates would decline. Accordingly, this research named factor 2 as 'obesity result perception factor'.

Table 4: Q-statements on obesity and Z-scores per factor $(\mathrm{N}=21)$

\begin{tabular}{|c|c|c|c|c|c|}
\hline \multicolumn{6}{|c|}{ Representative items of type } \\
\hline Factor & Type & No & Representative items & Mean(SD) & Z-score \\
\hline \multirow[t]{3}{*}{$\begin{array}{l}\text { Factor1 } \\
(\mathrm{N}=14)\end{array}$} & Type1 & 10 & $\begin{array}{l}\text { Obesity can cause diseases like high blood } \\
\text { pressure, and diabetes, etc. }\end{array}$ & $8.79(0.975)$ & 2.14 \\
\hline & & 33 & Overeating by stress can cause obesity. & $8.43(1.342)$ & 2.01 \\
\hline & & 6 & $\begin{array}{l}\text { Obesity occurs by wrong eating habits and } \\
\text { intake of too much nutrition, }\end{array}$ & $7.29(2.234)$ & 1.27 \\
\hline
\end{tabular}


Table 4: (Continued)

\begin{tabular}{|c|c|c|c|c|c|}
\hline \multicolumn{6}{|c|}{ Representative items of type } \\
\hline Factor & Type & No & Representative items & Mean(SD) & Z-score \\
\hline & & 35 & $\begin{array}{l}\text { The increasing frequency of eating out and } \\
\text { dining together raises the probability to } \\
\text { become obese. }\end{array}$ & $7.21(1.718)$ & 1.18 \\
\hline & & 14 & Obesity stress can lead to overeating. & $7.07(1.542)$ & 1.10 \\
\hline & Typez & 5 & $\begin{array}{l}\text { I think that my friends despise me because I } \\
\text { am fat. }\end{array}$ & $3.29(1.437)$ & -1.70 \\
\hline & & 1 & $\begin{array}{l}\text { Obesity makes me difficult to have a smooth } \\
\text { relationship with colleagues, seniors and } \\
\text { juniors. }\end{array}$ & $3.50(1.557)$ & -1.61 \\
\hline & & 7 & $\begin{array}{l}\text { Obesity makes it difficult to form self-iden- } \\
\text { tity. }\end{array}$ & $3.71(1.437)$ & -1.48 \\
\hline & & 15 & Obesity negatively affects sociality. & $3.43(1.604)$ & -1.42 \\
\hline & & 3 & $\begin{array}{l}\text { An obese person is regarded as an unattrac- } \\
\text { tive and ugly glutton. }\end{array}$ & $3.86(2.316)$ & -1.27 \\
\hline \multirow[t]{10}{*}{$\begin{array}{l}\text { Factor2 } \\
(\mathrm{N}=7)\end{array}$} & Tyрез & 10 & $\begin{array}{l}\text { Obesity causes various diseases like high } \\
\text { blood pressure and diabetes, etc. }\end{array}$ & $9.43(0.787)$ & 2.46 \\
\hline & & 6 & $\begin{array}{l}\text { Obesity occurs by wrong eating habits and } \\
\text { intake of too much nutrition, }\end{array}$ & $8.29(0.488)$ & 1.78 \\
\hline & & 9 & $\begin{array}{l}\text { Obesity makes it impossible to wear clothes } \\
\text { I want to. }\end{array}$ & $8.00(2.236)$ & 1.52 \\
\hline & & 4 & $\begin{array}{l}\text { Obesity makes one have an inferiority com- } \\
\text { plex about one's appearance. }\end{array}$ & $7.43(0.976)$ & 1.29 \\
\hline & & 24 & $\begin{array}{l}\text { Views on obesity care different in different } \\
\text { cultures. }\end{array}$ & $7.29(0.756)$ & 1.13 \\
\hline & Type4 & 21 & $\begin{array}{l}\text { An obese person is considered as having a } \\
\text { weak will and being low in scholastic scores. }\end{array}$ & $2.43(0.787)$ & -1.94 \\
\hline & & 1 & $\begin{array}{l}\text { Obesity makes me difficult to have a smooth } \\
\text { relationship with colleagues, seniors and } \\
\text { juniors. }\end{array}$ & $2.57(1.134)$ & -1.91 \\
\hline & & 27 & $\begin{array}{l}\text { I feel that my parents do not love me because } \\
\text { I am fat. }\end{array}$ & $2.71(1.113)$ & -1.63 \\
\hline & & 3 & $\begin{array}{l}\text { An obese person is regarded as an unattrac- } \\
\text { tive and ugly glutton. }\end{array}$ & $3.29(2.138)$ & -1.48 \\
\hline & & 18 & $\begin{array}{l}\text { Obesity makes me depend more on my } \\
\text { friends. }\end{array}$ & $3.16(1.773)$ & -1.45 \\
\hline
\end{tabular}

\section{DISCUSSION}

The analysis found that there are two factors in subjectivity perceived by nursing students: factor 1 is 'obesity cause finding factor'; factor 2 is 'obesity result perception factor'. The characteristics of each factor are as follows.

Those belonging to factor 1 focus on the causes of obesity. They assume that if one knows what causes obesity, one can prevent it. As obesity occurs by long-time living habits and eating life, it is not easy to escape from it. Thus, it is important to have the education to teach people how to prevent obesity.
Major obesity treatment and prevention methods are diet, exercise, behaviour change, medicine, and surgery, etc. Behaviour change which has frequently been adopted up to now is based on the assumption that wrong eating habits and lack of activity cause obesity. It is the treatment method to change one's problem by analyzing one's behaviour through selfobservation method. However, as behaviour change is not enough to lose weight, it is more effective when diet regulation is accompanied. ${ }^{18}$ Therefore, to prevent or control obesity, in particular, of middle-aged women, it is necessary to improve living habits and eating habits which are cheap and few side effects and increase energy spending with aerobic 
exercises. ${ }^{19}$ However, while most people know that exercise is important, it is difficult to keep exercising schedules for a long time. $50 \%$ of people who started exercises stop in 3-6 months..$^{20}$ Thus, it is necessary to develop an obesity management program, considering the merits and demerits of various exercises, which can guide obese people to voluntarily participate in.

Recently, with the improvement of income level, and the development of food industry caused by active trade with foreign countries, Korean eating life has become westernized. Along with it, increasingly more people consume processed food and instant food, leading to a rapid increase in the ration of the obese population. In particular, there is a social trend among young generations favouring thin body shape, and some of the young women who have normal body weight in body mass index (BMI) perceive themselves as being overweight compared with women appearing in mass media, and lose self-confidence or have psychological anxiety. ${ }^{21}$

The mass media, which strongly influences the people, should represent the correct image of the bodily beauty of human beings with social responsibilities. Newspapers, magazines, internet portals and TVs should provide correct information on the diet with social responsibilities. Diet information should be continuously monitored and regulatory authority should oversee and restrain excessively commercial and unhealthy advertisements and information according to relevant laws and regulations with enactment whenever necessary. Also, our schools should educate students so that they can discern helpful information by themselves. Lastly, a specific strategy for improvement of health should be established by experts to implement a diet that can improve our health.

Nursing students experience a lot of stress from heavier study burden than other of other majors, insufficient knowledge and experience they recognize in clinical training, insufficient autonomy, difficulty in adjusting themselves in the requirements of observing ethical norms as professional nurses. ${ }^{22}$ Besides, physically and socially, they, placed in the transition to adulthood, should play the role of health model to their nursing objects. Thus, they need to keep an ideal eating life.

Factor 2 is 'obesity result in perception factor'. Those who belong to factor 1 are concerned about the results of obesity. They assume that as obesity results in health problems that can cause chronic diseases and appearance problems, it should be overcome. However, the view that such results of obesity are viewed differently in different cultures, and that obese men do not have socio-psychological problems.

While obesity is a problem in itself, it causes serious problems physically. So, we need to pay attention to it. Physical problems that can be caused by obesity are high blood pressure, diabetes, hyperlipidemia, metabolic syndrome, orthopaedic problems, and eating disorders, etc. ${ }^{23,24}$ While there have been not many researches linking obesity to psychological health problems, previous researches have found that it can harm self-esteem, and is related to being stigmatized by those who hear them and melancholy, etc..$^{25,26}$ Thus, it is undeniable that obesity is closely related with physical and mental health. Martin-Lopez et al. (2011) go further and pointed out that obesity is related to life quality and psychological well-being. However, there have not been sufficient empirical studies linking obesity with psychological wellbeing, more studies are required. ${ }^{27}$

Obesity generates psychological problems like depression, stress, personality disorder, and dissatisfaction with appearance, which causes avoidance of human relations and lowering of self-esteem, working as a serious threat to life quality. ${ }^{28,29}$ Because of that, obese people try various means to lose weight such as diet, exercise therapy, behaviour change therapy, drug use, and oriental medicine therapy, etc. However, the effects of most of the treatments are not very effective, or just temporary. And, as they repeatedly fail in regulating body weights, their self-esteem declines, and they become passive. In extreme cases, they fall into anorexia or binge-eating disorder. So, it is necessary to develop means of nursing intervention to manage difficulties fat people experience in the process of regulating their weights, and, to do it, it is necessary to examine weight regulating experiences of obese people in advance.

Especially, what has recently become problematic, obesity-related life quality, is the consideration of personal life quality influenced by obesity. It has become an increasingly important concept in obesity-related studies..$^{30}$ Many female college students tend to regard that they are overweight. In reality, the quality of life of overweight students is lower than that of normal weight students. It is also true for those who are not satisfied with the results of weight regulation. ${ }^{31}$ The higher real obesity level or obesity level as one feels is, the higher obesity stress is. ${ }^{32}$ Thus, it is necessary to search for various weight management programs to raise obesityrelated life quality.

This study examined the subjective perception of obesity of nursing students and classified it into 2 factors. Such research on subjectivity can be used as basic data for developing an educational program on obese people. Besides, it is expected that this study offering subjectivity structure of perception on obesity among nursing students and characteristics of each factor of the structure will be used for basic sources for developing an educational program on it. ${ }^{33-35}$

However, it has limits in generalizing the findings in the sense that the analysis is based on students in a specific college, and that participants were not selected considering factors affecting perceptions on obesity. It is necessary to explore the Q sample based on various backgrounds. ${ }^{36-38}$ 


\section{CONCLUSION}

This study was performed to examine subjective perceptions on obesity of nursing students and provide basic data needed to explore ways to activate researches on obesity using Q methodology. The analysis extracted 2 factors: obesity cause finding factor and obesity result perception factor.

The above results are thought to be helpful to understand the structure of awareness of how nursing college students perceive obesity. However, this research analyzed 21 nursing college students and it is difficult to generalize the perception of obesity. Therefore, we hope that repetitive research on nursing college students and nurses will be carried out based on the results of this research, and based on a correct perception of obesity, we hope that the development of educational programs will help nursing students adapt well as nurses. ${ }^{39,40}$

This study, by categorizing subjectivities on obesity of nursing students, provides basic sources needed in obesity reduction support system. It is expected that this analysis can help policymakers to develop educational programs considering characteristics of each factor of subjectivities. Plus, this study suggests further qualitative researches on obesity to identify various factors which affect the nursing of obese patients by developing Q samples considering various factors. ${ }^{39-41}$

Acknowledgement: Authors acknowledge the immense help received from the scholars whose articles are cited and included in references of this manuscript. The authors are also grateful to authors / editors / publishers of all those articles, journals and books from where the literature for this article has been reviewed and discussed.

\section{Conflict of Interest: Nil}

Source of Funding: Nil

\section{REFERENCES}

1. Yoo WH. Effects of body composition, blood lipids and fitness factors as the polymorphism in the $\beta 3$-AR gene and ACE gene of obese children on aerobic exercise. Sookmyung Women's University, Graduate School. 2006.

2. Bray GA. Medical consequences of obesity. The Journal of Clinical Endocrinology \& Metabolism. 2004 Jun 1;89(6):2583-9.

3. Clark JM. The epidemiology of the nonalcoholic fatty liver disease in adults. Journal of clinical gastroenterology. 2006 Mar 1;40:S5-10.

4. Haslam DW, James WP. Obesity Lancet, 366 (9492), 1197 1209. Health Physics Society (2009) Online, available at www. hps. org/public information/ate/q535. HTML. 2005.

5. Wadden TA, Butryn ML, Sarwer DB, Fabricatore AN, Crerand CE, Lipschutz PE, Faulconbridge L, Raper S, Williams NN. Comparison of psychosocial status in treatment-seeking women with class III vs. class I-II obesity. Sur. Obes.Related Dise. (SOARD). 2006 Mar 1;2(2):138-45.
6. Bray GA. Medical consequences of obesity. The Journal of Clinical Endocrinology \& Metabolism. 2004 Jun 1;89(6):2583-9.

7. Kim EJ, Cha BK. Weight control behaviours in female college students. Korean Journal of Women Health Nursing. 2007 Dec 1;13(4):320-6.

8. Choi YR. Obesity stress and depression in elementary school students. Yunsei University, Master's Thesis. 1997.

9. Jeon YS, Ahn HS. Influence of subjective perception of body image and weight management on obesity stress in college women. Journal of the Korean Society of Esthetics \& Cosmeceuticals. 2006;1(2):13-26.

10. Shin EJ, Park YS. Emotional intelligence, ego resilience, the stress in the clinical practice of nursing students. Journal of the Korea Academia-Industrial Cooperation Society. 2013;14(11):5636-45.

11. Wong CS, Law KS. The effects of leader and follower emotional intelligence on performance and attitude: An exploratory study. The leadership quarterly. 2002 Jun 1;13(3):243-74.

12. Dyess S, Parker CG. Transition support for the newly licensed nurse: A programme that made a difference. J.Nurs. Mana.. 2012 Jul;20(5):615-23.

13. Park HH, Jang MY. The effect of nursing students' smartphone addiction and emotional intelligence level on quality of life. Journal of the Korea Entertainment Industry Association. 2017 Feb;11(2):217-27.

14. Whang SM, You SW, Kim JY, Kim RG. Consumer Types and Cultural Consumption Characteristics of Korean Society: Who Spends for What Reasons. Journal of Human Subjectivity. 2006;13:25-39.

15. Lee H., Jang S., Wang M. A Study on Patients' Perceptions of Patient Safety (Q method). Asia-pacific Journal of Law, Politics and Administration. 2017 Oct;1(2):1-6.

16. Wang M., Jang S. A Study on the Subjectivity of Nursing Students on Dating Violence. International Journal of Advanced Nursing Education and Research. 2017 May;2(1):97-102.

17. Jang S. The Subjectivity for Open Adoption of Nursing Students. International Journal of Advanced Nursing Education and Research. 2018 May;3(1):59-64.

18. Faith MS, Fontaine KR, Cheskin LJ, Allison DB. Behavioural approaches to the problems of obesity. Behaviour Modification. 2000 Sep;24(4):459-93.

19. Ballantyne D. Prescribing exercise for the healthy: assessment of compliance and effects on plasma lipids and lipoproteins. Health Bull.. 1978;32:169-79.

20. Kim HD, Park JS. The effect of an exercise program on body composition and physical fitness in obese female college students. Journal of Korean Academy of Nursing. 2006 Feb 1;36(1):5-14.

21. Kang KS. The body mass index (BMI), body image recognition, weight control behaviour of nursing students. Journal of the Korea Academia-Industrial Cooperation Society. 2012;13(8):34929.

22. Kwon YS. A study on obesity stress and related factors among female college students. Journal of Korean Academy of Community Health Nursing. 2008;19(3):431-42.

23. Busija L., Hollingsworth B., Buchbinder R., Osborne R. H. Role of age, sex, obesity in the higher prevalence of arthritis among lower socioeconomic groups: a population-based survey. Arthritis\&Rhumatism 2007;57:553-561.

24. Koebnick C., Smith N., Huang K., Martinez M. P., Clancy H. A., Kushi L. H. The prevalence of obesity and obesity-related health conditions in a large, multiethnic cohort of young adults in California. Annual Epidemiology. 2012;22:600-616. 
25. Scott KM, Bruffaerts R, Simon GE, Alonso J, Angermeyer M, De Girolamo G, Demyttenaere K, Gasquet I, Haro JM, Karam E, Kessler RC. Obesity and mental disorders in the general population: results from the world mental health surveys. International journal of obesity. 2008 Jan;32(1):192-200.

26. Simon GE, Von Korff M, Saunders K, Miglioretti DL, Crane PK, Van Belle G, Kessler RC. Association between obesity and psychiatric disorders in the US adult population. Archives of general psychiatry. 2006 Jul 1;63(7):824-30.

27. Martín-López R, Pérez-Farinós N, Hernández-Barrera V, de Andres AL, Carrasco-Garrido P, Jiménez-García R. The association between excess weight and self-rated health and psychological distress in women in Spain. Public health nutrition. 2011 Jul;14(7):1259-65.

28. Dong C, Sanchez LE, Price RA. Relationship of obesity to depression: a family-based study. International journal of obesity. 2004 Jun;28(6):790-5.

29. Lee SH, Hyun MH. The effects of obesity, body image satisfaction, and binge eating on depression in middle school girls. Korean Journal of Health Psychology. 2001;6(1):195-207.

30. Duval K, Marceau P, Pérusse L, Lacasse Y. An overview of obesity-specific quality of life questionnaires. Obesity reviews. 2006 Nov;7(4):347-60.

31. Chaung SK, Kim CG. Obesity-related quality of life in overweight and obese female college students. Journal of Korean Academy of Community Health Nursing. 2007;18(4):543-51.

32. Kwon YS. A study on obesity stress and related factors among female college students. Journal of Korean Academy of Community Health Nursing. 2008;19(3):431-42.
33. Ogden J, Hoppe R. Changing practice nurses' management of obesity. Journal of Human Nutrition and Dietetics. 1998 Jun $1 ; 11(3): 249-58$.

34. Green SM, McCoubrie M, Cullingham C. Practice nurses' and health visitors' knowledge of obesity assessment and management. Journal of human nutrition and dietetics. 2000 Dec;13(6):413-23.

35. Longhurst C. Government plan for nurses to tackle obesity. Nursing Standard (2014+). 2016 Aug 24;30(52):9.

36. Jang S., Wang M. The Subjectivity Study on the Perception of Low Fertility in College Students. International Journal of ITbased Public Health Management. 2018 Jul;5(2):13-18.

37. Wang M., Kim S., Jang S. Study of Subjectivity on Death in Korean Elderly. International Journal of Elderly Welfare Promotion and Management. $2018 \mathrm{Jul} ; 2(2): 37-42$.

38. Jang S. Subjectivity for infertility of nursing students. International Journal of Advanced Nursing Education and Research. 2017 May; 2(1):91-96.

39. Warren L. Can nurses be positive role models in the obesity fight?. Nursing Standard. 2008 Sep 24;23(3):33-4.

40. Kelly M, Wills J. Systematic review: What works to address obesity in nurses?. Occupational Medicine. 2018 May 23;68(4):228-38.

41. Jang S. A Study on Subjectivity about Obesity among Nursing Students. Journal of Healthcare and Medical Technology. 2020;1:7-12. 